\title{
Las medias compresivas reducen a la mitad la incidencia de síndrome post-trombótico
}

Brandjes DPM, Büller HR, Heijboer H et al. Randomised trial of effect of compression stockings in patients with symptomatic proximal-vein thrombosis. Lancet 1997, 349:759-62.

\section{Objetivo}

Valorar el efecto preventivo de medias compresivas sobre el síndrome post-trombótico (SPT), tras el primer episodio de trombosis venosa profunda (TVP) proximal.

\section{Diseño}

Estudio prospectivo randomizado y controlado.

\section{Lugar}

Dos centros médicos en Amsterdam, Holanda.

\section{Pacientes}

Pacientes con un primer episodio TVP proximal (poplítea o por encima) documentada por flebografía, derivados a los centros por sus médicos de familia. Se excluían a aquellos pacientes con expectativa de vida menor a 6 meses, TVP bilaterales, procesos varicosos extensos o ulcerados, uso actual de medias compresivas y paraplejía.

\section{Intervención}

Los pacientes se randomizaron al grupo medias: GM (elásticas, compresivas y graduadas en 40, 36 y $21 \mathrm{mmHg}$ en tobillo, pantorrilla baja y alta respectivamente) o al grupo control sin medias: GC. Todos los pacientes recibian heparina hasta 5 días postexternación y 3 meses de warfarina. Las medias, hechas a medida del paciente, se aplicaban a las 2 o 3 semanas de la
TVP, utilizándose de día y por al menos 2 años. Luego los pacientes optaban por continuar usándolas o no. Investigadores independientes valoraron cada 3 meses los primeros 2 años y cada 6 meses por al menos 5 años, la presencia de SPT empleando scores de leve a severo, validados en base a criterios subjetivos (dolor de pantorrilla espontáneo, en reposo, de pie o caminando) y objetivos (aumento de la circunferencia de la pierna, nuevas várices o úlceras venosas). Para diferenciarlo de síntomas asociados a la TVP inicial se hizo diagnóstico de SPT solo después de 6 meses.

También se valoró cumplimiento y recurrencias de TVP o tromboembolismo pulmonar.

\section{Medición de Resultados}

Incidencia acumulativa de SPT leve a moderado.

\section{Resultados principales}

De 315 pacientes consecutivos , 44 fueron excluidos y 77 no aceptaron participar, quedando 194 (96 GM y $98 \mathrm{GC}$ ). El seguimiento medio fue 76 meses en ambos grupos. El SPT leve a moderado ocurrió en $20 \%$ del GM vs $46 \%$ del GC ( $p<0.001)$ y el SPT severo en $11 \%$ del GM vs 23\% del GC (p<0.001). En ambos grupos la mayoría de los SPT ocurrió dentro de los 24 meses de la TVP.

\section{Conclusiones}

El 60\% de los pacientes con un primer episodio de TVP proximal desarrollan SPT dentro de los 2 años. Las medias compresivas graduadas redujeron esta incidencia en aproximadamente un $50 \%$.

\section{Comentarios}

Hay varios puntos que dan fuerza y trascendencia a este estudio. La intervención es fácilmente aplicable, los pacientes similares a los de nuestra práctica y el tratamiento factible (validez externa). Respecto a la veracidad de los resultados (validez interna) importa la adecuada randomización de un número de pacientes previamente calculado, que tanto los participantes como los que rehusaron participar eran de iguales características; y que el seguimiento fue de casi el $80 \%$ de los pacientes, informándose las causas de quienes no lo completaron. Si bien no existe una definición aceptada de SPT se utilizó un score clínico ya probado
(1) que incluye criterios objetivos y que a favor de su precisión, encontró reducciones similares tanto en los casos leves a moderados (requerimiento diagnóstico mínimo) como en los severos. A pesar del diseño no ciego (uso de medias) que podría sesgar la valoración de los grupos, el uso cuantitativo de scores, la obligación de diagnosticar SPT en 2 seguimientos consecutivos por diferentes investigadores que desconocían la valoración anterior y la interpretación de los scores por un comité independiente, limitaría este sesgo. Aunque el estudio no investigó el tiempo de uso óptimo de medias, dada la infrecuencia de SPT luego de los 2 años, parece razonable asumir que las medias deberían aplicarse por un mínimo de ese lapso.

\section{Dr. Agustín Ciapponi \\ Unidad de Medicina \\ Familiar y Preventiva}

Hospital Italiano de Buenos Aires

Referencias

1. Villalta S, Bagatella P, Lensing AWA et al. Assessment of validity and reproducibility of a clinical scale for the postthrombotic syndrome.

Haemostasis 1994; 24: 158a 